In the use of ancesthetics, we find now rising a revival of the rivalry between chloroform and ether, which the fame and support of the late Sir James Y. Simpson had decided in this country in favour of the former. We follow but tardily, in this old country, in that combination of pleasure with utility which has led lately the inventive genius of our transatlantic brethren to the association of rsthetics with anæsthetics in the performance of operations under these agents to an obligato accompaniment upon the organ, and an appropriate address by a popular preacher, improving the occasion on behalf of morals. The comparative safety of these agents is unquestionably a most important point, and one that must ultimately decide the mat. ter in favour of that anæsthetic the use of which involves the fewest casualties. The chief difficulty in determining this is the natural disinclination to make public such cases. It is less oljectionable, however, to do so when a certain lapse of time has occurred after the accident; and it is to be hoped that, in the not very far future, we may arrive generally at that philosophic frame of mind which will consider it as much a duty to publish unsuccessful cases as it is a gratification to achieve the glory of a brilliant result.

In the domain of surgery, gentlemen, are so many regions now undergoing exploration and re-examination, that I may fairly claim an excuse for having led you chiefly over ground which I have myself travelled, and for omitting many equally important territories perhaps more effectively mapped out, and to some of you more interesting. In exploring this domain, many pioneers are required, and many very qualified ones are busily at work. Those who have skill and pluck enough to find a new road of investigation, even if it be only to prove that it leads no whither, deserve commendation for this proof, which is itself good work done. 'They demand our sympathy, perhaps, more than those who are lucky enough to lead up to the most auriferous diggings. The age we live in is too much given to the worship of success to afford much of this sympathy; and it accords, usually, too little merit to such as have contributed to prepare a way for the honour which another has reached, profiting, it may be, by their mistaken vestiges in travelling upon the same errand. As we advance, our horizon itself' extends; the very multitude of objects brought into view perplexes the perception of them; and even our instruments for detecting and examining them become so numerous as to be themselves impedimenta to our progress. The difficulty of deciding upon any given point becomes greater as differences become more minute, and proof more complex and further from our standpoint. The use of the imagination in science has already been powerfully justified; and the time may yet come when a complete and logical proof will bo as little possible in scientific knowledge as in dogmatic theology. The theory of probabilities will doubtless be more employed to compensate for the imperfection of the record, and may be turned to advantage in archebiosis and the germ-theory, as much as in the Darwinian. It will thus become easier for the critic to fall into the error of asking for more evidence than the nature of the subject admits of - a sure sign of the limited area of his habitual observations. But even this tendency is productive of good. It is merely the redundant energy of a single-minded instinct in this natural enemy of invertors and innovators-sent, doubtless, as hawks to keep down sparrows, to insure proper limits and decent order among the more imitative minds who follow, prove, and sometimes improve, upon originators, and form schools and fashions. They thus accumulate a chastened experience. When weighted by the synthetical faculty, this instinct constructs eclectic systems, more than ever needed in the present chaos of crude ideas and undigested opinions, to which these swift-winged writers are fearsome scourgers. By their keen research they discover when and how things are re-invented and re-discovered, show the limits of their application, give warnings of danger and excess, which, if often falsified, at least inspire an useful caution, or lead to a more insured confirmation. Still more useful are they in deciding when discoverers disagree about priority. Whether right or wrong, they ultimately have the effect of consolidating and rendering more certain a well-grounded reputation. Misled by the Chasles forgeries, they found out that Newton had been preceded in his discovery of gravitation by a French savant, and thus elicited an elaborate and con. clusive proof of its great originality. They have lately asserted that Harvey had been forestalled in his discovery of the circulation of the blood by Walter Warner, and have thus given us the benefit of the profoundly learned vindication of the Linacre professor of anatomy and physiology at Oxford.

A still greater influence and responsibility than heretofore will rest upon these labourers in science. The fruition of really great dis. coveries has been, and will, no doubt, continue to be, postponed by the blind opposition of those who form the scientific opinions of the age, and, though they usually check one another, so as to act, on the whole, with advantage, yet their neglect or prejudices may undoubtedly prevail, so as to inflict injustice upon individuals, and do injury to science and to mankind, the more lasting in proportion to their position, ability, and conscientiousness.

\section{ADDRESS IN PHYSIOLOGY,}

BY

\section{JOHN BURDON SANDERSON, M.D., F.R.S., Professor of Practical Physiology in University College.}

THE subject on which I have to address you to-day is Physiology, but we are met for the purpose of promoting the progress of medicine. We are, I venture to say, rather a practical than a scientific body, having ends and aims which concern our own good and that of the community, rather than the promotion of science. Yet, notwithstanding, we all feel that we take a great interest in science, not only in those branches of it which have to do with our every-day work, but in those which have little or no connection with our art.

There exists, I doubt not, in the minds of all of us, a conviction that science possesses a certain intrinsic value not dependent on its immediate applicability to useful ends. Every day we, like other men, are become ing more and more convinced that it is a desirable thing to search after truth by the observation of nature-that those who occupy themselves in this pursuit are substantial benefactors of their country and of the human race - that the scientific labours of a few men, who do not set forth philanthropy as their motive, who do not profess to sacrifies themselves for the good of mankind, who live quiet unobtrusive lives, and are known for the most part only by their work, may accomplish more for the material welfare of the community than the efforts of armies of philanthropists. If I were to attempt to illustrate this, I should have to turn to other subjects than those which we have before us, for physie ology has as yet done little for our art, and, consequently, little for humanity. I should have to seek for examples among the professors of those sciences which are sufficiently advanced to be brought into practical application. When I think of a life like Faraday's, every year of which brought a new accession of knowiedge, and in the end enriched this country to such a degree as ought to secure him the posthumous adoration of all Mammon worshippers, however little they thought of him when alive; and when we compare the results of his life with the life itself, with the contracted laboratory in which he laboured, with the mean salary on which he lived, with his quiet devotion to science, with the constancy of his religious faith, and finally with the end of that life-mind and body exhausted in work - how great in such a man does that insatiable spirit of inquiry seem, which finds its constant and all-sufficient pleasure in the discovery of new truth-in wresting from Nature her secrets by strenuous intellectual effort!

In an address, which $I$ had the honour of giving at the opening of the Physiological Section of the British Association, I endeavoured to com. bat the now prevailing view, entertained by many men of science, that it is desirable, in the interests of Physiology, that it should be as completely as possible separated from medicine, on the ground that, being founded on experimental research, and using the same methods of investigation as are used in the sciences of physics and chemistry, it ought, for all purposes of teaching and study, to be regarded as part of them. I was then addressing an audience of zoologists and botanists, scarcely any, or at all events few, of whom were medical men. I was, therefore, not surprised that the views then expressed as to the necessary connection which exists between Medicine and Physiology, were strongly objected to, and that my belief in the association of practical medicine with any subject deserving the name of a science was attributed to my own professional bias.

I founded my argument on the natural relation which must always exist between every art and the sciences on which it is founded ; maintaining that to try to separate medicine from Physiology would be as unreasonable as to separate telegraphy from electricity, engineering from mechanics, or navigation from astronomy.

When I was called upon to deliver the address on Physiology before this Association, I at once determined to follow out the same line of thought - not going over the same ground, but pursuing it in a direction which was before precluded, and which would have neither fitted the occasion, nor the composition of the audience at Brighton. Then it was necessary to look at the question from the side of physical science, now I propose to look at it from the side of medicine. 
The subject is, I think, one of considerable importance both to medicine and to physiology, but also of considerable difficulty. Conscious of this, I should not have made bold to take it up, had I not felt that I could entirely depend on your sympathy and indulgence.

I have no doubt that we are all agreed in entertaining a high opinion of the value of Physiology, and that we are all anxious to promote its progress. Beyond this, I should not be surprised to find very great differences of opinion. There are probably some who think that every physician ought to be a physiologist-that in the selection of remedies and the diagnosis of disease he ought to call in the aid of physiological considerations, and be guided, not merely by experience (or by empiricism as we call it when we want to slight its value), but also by science. Freely admitting that Physiology is scarcely as yet sufficiently advanced in the work of investigation to advise safely on practical subjects, they would look forward to a time when it will be otherwise ; believing that, as the science approaches maturity, it will assume an authority in the decision of practical questions to which now it has no just pretensions. I am convinced, however, that this is not the view usually entertained by the profession at large. The opinion certainly most common is that, although Physiology may be a very good thing in its place, conclusions derived from physiological reasoning ought always to give way to the dictates of practical experience, and that science never can be a guide to practice. Those who en ploy this mode of expression refer, as to a convincing argument in support of it, to the numerous instances in the history of medicine in which the influence of what they are pleased to term physiological theory has been injurious.

They refer, e.g., to the overfeeding and overstimulating treatment of disease during the last twenty years ; to the unreasonable disuse of venesection; to the neglect of antimony and other so-called antiphlogistics ; to the undervaluing of mercurial remedies; to the purgative treatment of cholera ; and to other instances in which they say that practical medicine has been injured by allowing phy'siological theory to dominate over experience.

With the exception of the misapplication of a single word I have not very much to object to in the view so expressed. But that word, in relation to the subject of my present discourse, is somewhat im. portant. It is the word "physiological"! The cases on which the whole argument is founded are undoubtedly good examples of the injury done to medicine by allowing theory to dominate over practice ; but in no single instance can the theory referred to be termed, with any regard to exactitude of expression, physiological. Take the example of mercurial remedies as the most familiar, and as having relation to a therapeutical investigation, set on foot some years ago by this Association. What is the state of the case ?

Physiological experiment has proved that mercury exercises no influence in increasing the secretion of the liver. Experience had proved ten thousand times that, in certain sufficiently well defined disturbances of the digestive organs, the traditional blue pill and black draught at once relieve the symptoms, and restore the disordered functions to the normal, and the patient from misery to comfort. These are the two facts, the one physiological, the other practical or empirical. Out of these spring two theories; one that mercurial remedies are useless, the other that mercury acts beneficially by exciting the secretion of bile. Both are demonstrably false. The former, certain writers on the subject are pleased to call physiological. All I can do on the part of physiology is to repudiate it altogether. It is an inference which practical men, and not physiologists, have with insufficient consideration drawn from physiological facts. It is an example, in short, not of the injury which physiology does to medicine, but of the undeserved discredit which practical men throw upon science, by attempting to apply its facts without any sufficient knowledge of their bearing.

I have entered upon these considerations for the purpose of showing that, in the present position of Physiology and Medicine, it is highly desirable for the welfare of both to draw a distinct line of demarcation between them. On the one side of this line we have what may be properly called the science of medicine; a science in which experiment has no place, its fundamental facts being gathered, not from experiment, but from case-books and the records of post mortcm examinations. Its method consists in systematising and combining the experience of great numbers of trustworthy persons in such a way as to make them applicable to diagnosis and treatment, and admits of being carried out with quite as much exactitude as those methods which are employed in the so-called exact sciences.

In Physiology, comprising its two branches, pathology and pharmacology, experiment is everything. Just as the science of medicine proper may be described as based on the observation of cases, and in the orderly classification of the recorded clinical facts, so physiological science is built up of experimental results. Its mode of working is that which is now understood by the term research, the nature of which is best ex. pressed by the well-known words of Harvey, in founding the Harveian oration, in which he declares his purpose to be that the orator should stir up his hearers to search out the secrets of nature by way of experiment.

The distinction between medicine as an empirical, and Physiology as an experimental, science, though easy to state, is difficult to maintain practically. For, between the two regions of experience and research, there lies an intermediate territory of speculation, which is a constant source of temptation even to the most practical mind. Whether he will it or not, he is constantly led by the subjects which occupy his thoughts in practice to speculations on the nature and origin of disease. For every intelligent man-every man who is possessed of that insatiable desire to understand all that he observes, which is the basis of all intellectual effort-has constantly presented to him, in the practice of our profession, facts which furnish the very stimulus required to call the speculative tendency into action. Already practised in the faculty of accurate observation, he is constantly being tempted to undertake the work of investigation ; in other words, not to content himself with the appreciation of the facts which bear upon diagnosis and treatment, but to engage in inquiries relating to the intimate nature, the origin and essence, of the diseased processes he has before him.

Is it either possible or desirable to check this tendency to speculation? Certainly not. So long as practical medicine lasts, and the minds of men are constituted as they are, speculation will continue. Practical men will still make excursions into this border land of imagination ; will still make advances, so to speak, towards Physiology. Our efforts, therefore, ought to be, not to prevent speculation, not to reject these advances, but, on the contrary, to advance on our side to meet them. For the process by which we get new knowledge is a reciprocal one-theory and experiment, question and answer. The practical mind suggests and theorises; the physiologist doubts, experiments, and tries to answer. Or, putting it in terms more directly applicable to our subject, the clinical observer analyses the facts of disease, separating them from each other, and ascertaining, by the application to the case of the numerical method (the great instrument of his science), which are the most important, i.e., the most constant characteristics of the disease, and in this way sets questions. The experimental man begins his investigations where the other terminates his analysis; and sets to work, not on the whole disease as it presents itself in its complication of phenomena, but on the simpler processes, such, e.g., as fever, inflammation, catarrh, into which the clinicist has resolved it. With these he proceeds by the same methods as are used in all the other experimental sciences. Having a phenomenon, he seeks for its cause, directing his efforts to the discovery, among the perhaps numerous conditions to which it may be attributed, of the one on which it is actually dependent, and by means of which it can always be reproduced.

In this way both the speculative and the sceptical faculties of the mind are brought into useful exercise-the function of the one being to set questions on the behalf of clinical medicine, of the other to answer them by experiment. So long as this reciprocal relation is maintained, there is no danger in speculation. The danger to science begins when the practical man not only asks his question, but gives his own answer in the name of science. The danger to practice is when he allows such answers, falsely given, to lead him astray from the safe guidance of experience.

I desire to illustrate this reciprocal influence of empirical speculation on the one hand, and experimental scepticism on the other, by a single example-endeavouring to show how, as I have said, both work together for the progress of pathology.

Before proceeding, however, I would guard myself against a misunderstanding. When I place the two functions of suggestive and experimental work, so to speak, in opposition, I do not mean that the two should not be exercised by the same person. For, although there may be conditions in the recent progress of science which render it necessary now, more than in former times, that there should be division of labour, we have abundant proof in the history of our science that the advances have been made by men who have looked at questions from both sides, in whose intellects imagination and doubt, question and answer, speculation and experiment, have had equal scope.

I now return to my examples. The one that I shall take is that of the Physiology of the Febrile State-a subject which, at the present moment, occupies the attention of a larger number of workers than any other question in pathology. And in pursuance of my plan, I will endeavour, first, to trace the development of the chief scientific theories which prevail on the subject-in other words, the questions which have been asked by clinical medicine and the responses of experimental science, and then to show in what direction permanent progress can alone be made.

I would state to you at the outset, that I shall not have to bring 
before you any brilliant scientific achievements. On the contrary, you will see that the more sceptically we test the answers already given, the less considerable will they appear in proportion to the numerous questions which still remain unsettled.

At the present moment, the theory of fever which exercises the widest infuence and is most generally accepted is that of Virchow, the main characteristic of which is that it places the fons et origo of the febrile state in the nervous centres. To deal with it I must carry you back to the year 185I, which may be considered as an era in the history of this subject, if not in the development of the science of pathology in general, inasmuch as it is from this year that the use of the thermometer as an instrument of clinical observation may be said to date. For it was in 1851 that Traube, physiologist and physician in one, published the earliest systematised thermometrical observations of febrile diseases.

As regards the doctrine of fever, the effect of the introduction of this method was to bring us back to the notion which is expressed in the old Hippocratic word "pyrexia"-a word which implied the recognition of increase of temperature as the essence of the febrile state. For among the earliest results of the observations of Traube and his immediate followers was the demonstration of the fact-which no one had suspected before-that in fever the elevation of bodily temperature is characteristic of the whole process; and that in those fevers in particular in which the cold and the hot stage are most distinct from each other, the condition of the patient is as truly pyrexic in the former as in the latter, however little it may seem to be so to himself or to others ; in short, that amid all the varieties in the subjective state of the patient, in the state of the skin and of the circulation, the objective fact of increased temperature remains.

The immediate expression of the impulse thus given to the pathological thought in reference to fever was the development of the theory of Virchow just referred to. Founded directly on clinical observations, it seeks, like other theories of similar origin, to harmonise these ob servations with each other by regarding them as parts of the same physiological process. The first step in its construction was to bring the two chief components or constituents of fever-viz., pyrexia and increased discharge of oxidation products-into causal, i.e., physiological relation with each other.

Virchow's is essentially a neurotic theory. It points to the functional disorder of a hypothetical nervous centre, the so-called regulation or moderation centre, the exact position of which he does not pretend to determine, assigning to it, however, a place somewhere in the intracranial part of the spinal cord. The normal function of this centre is to preside over the bodily temperature; for it is owing to its agency that the oxidation-processes, which may be said to constitute the life of our tissues in health, are so controlled that the bodily temperature, even in the most internal parts, never rises above Ioo deg. Fahr.

In disease-i.e., in fever-the wholesome influence of this centre is paralysed, and the normal oxidation-processes gain the upper hand, as shown by the increased discharge of oxidised products by the lungs and kidneys, and the general wasting of the body, while the temperature rises.

Here I must ask leave to make a digression. While all this was going on in Germany, our own countryman Parkes was observing without theorising in England. So early as 1853, he had made both thermometrical observations and urine analyses in fever, which so far confirmed those of German observers. The results of his observations were published in his Gulstonian lectures on pyrexia. In these lectures, while concurring with Virchow in regarding fever as primarily a neurotic process-a process having its primary seat in the nervous centres-and supporting this view by a variety of convincing arguments derived from clinical observations, he, with characteristic and wise caution, neither followed him into his physiological explanation, nor substituted any other theory for it. It is now twenty years since the lectures were published; and although they are full of facts and observations which at the time were new, I do not think they contain any expressions or statements which the author, if he were to republish them, would find it advisable to retract. The reason is that Dr. Parkes approached his subject in a truly sceptical mind, and refused to give way to the besetting temptation to physiologise. He contented himself with setting questions ; not that he failed to see with perfect clearness the theoretical bearing of the facts, but because he knew that Physiology was not at that time in a position to answer his questions with any approach to certainty. Would that other equally earnest inquirers were endowed with the same wise cautiousness!

To return to Virchow. As I said before, he made no pretension to assign any definite position to the supposed regulation centre, either anatomically or by physiological experiment. The first serious attempt to do so was made by Naunyn and Quincke many years afterwards.
The evidence was sought by the method usually followed in physiology. When the physiologist desires to find out what is the value of a particular organ in relation to a particular function, he observes the modifications which that function undergoes when the activity of the organ in question is either disturbed or annulled. In the case of functions of intracranial organs in general, this is a matter of great difficulty; still more is it a difficulty when the organ, like the hypothetical heat-centre, has its seat in the most vital part of the nervous system; for it is not possible to eliminate its activity without interfering with other important activities of neighbouring parts.

These experiments consisted simply in observing the effects of dividing the spinal cord on temperature, under different circumstances, at different heights-viz., at different distances from the medulla. Now ordinarily, when the spinal cord is divided in the cervical portion, the effect on temperature is very marked. The result of the operation is not only (I need scarcely say) to paralyse the voluntary muscles, but to paralyse the vascular nerves.

The consequence of this vaso-motor paralysis is (as has been ascertained by repeated measurement) to retard the circulation, diminish the work done by the heart, and diminish the temperature. The temperature sinks because heat is given off at the surface more rapidly than it is evolved in the tissues- $a$ fact which is proved by the observation that if the animal is wrapped in cotton-wool its cooling is delayed, though it cannot be wholly prevented; while, on the other hand, if its body is immersed in a conducting medium, such as water at the ordinary temperature, so as to favour the loss of heat at the surface, the depression of internal heat is correspondingly accelerated.

The experiment of Naunyn and Quincke may be regarded as an imitation or reproduction of the well known case of dislocation of the lower cervical vertebræ recorded by the late Sir Benjamin Brodie, in which he observed a very rapid increase of temperature with acceleration of pulse before death. Having destroyed the continuity of the spinal cord by crushing at the level of the sixth or seventh cervical vertebræ, Naunyn and Quincke observed that, if the animal were placed in a chamber at a temperature varying from 82 to $86 \mathrm{Fahr}$., there was always an elevation of temperature amounting to three or four degrees, which, as in Sir Benjamin Brodie's case, was continued until death. This they attributed to the severance of those channels by which, according to the theory of Virchow, the intracranial part of the spinal cord controls those chemical processes by which heat is produced.

Having repeated the experiments of Naunyn and Quincke on one or two occasions, and failed to obtain any warming effect which could not be accounted for otherwise, I was not surprised, and was indeed somewhat gratified, to find that Professor Rosenthal, in an extensive series of experiments, had come to the same negative result-that is to say, had found that in all cases of division of the cord in the cervical region the effect of the operation is to depress the bodily temperature below the normal standard. The error of Naunyn and Quincke was evidently due to their having neglected to compare carefully the phenomena produced under the influence of the agent to be investigated with those which present themselves under otherwise similar conditions. For it is an invariable rule in experimental investigation, that no result can be accepted as proving the parentage of any given phenomenon, until it has been shown by counter-experiments that the effect is not produced under circumstances which, in every other respect excepting the presence of the supposed cause, are identical with those of the original experiment.

With these recent observations of Rosenthal, the history of the regulation centre theory may for the moment be said to terminate. It has not been definitely proved that the encephalon contains no such centre, but its existence has been rendered extremely improbable. For, although a great number of experiments have been planned for the ex. press purpose of eliciting evidence of its action, all have failed. In few words, the history of the theory is this : Framed to account for clinical facts, it was for years accepted by clinical pathologists as a good physiological explanation, until at last its importance claimed for it the attention of experimental physiologists, when it was found not to stand the test of investigation.

I now proceed to other theories having this in common, that while they place the origin of the febrile state in disturbance of the nervous system, they explain the influence of that disturbance in the production of pyrexia by supposing it to be exercised through the organs of circulation. There are two such theories, which are of sufficient importance to merit attention. One of them is endorsed by Traube, to whose clinical researches at the beginning of the present era in pathology I have already made reference; the other has attached to it the name of the distinguished French physiologist with whose presence we are now honoured. Thrown out by him in a lecture, probably rather as a sug. gestion than as a mature theory, it has received from medical theorists 
an extent of application which one may venture to suppose that its reputed author did not contemplate.

Both theories take their start from the ordinary physiological doctrine of the distribution of heat in the bodies of warm-blooded animals. As set forth with admirable clearness by Huxley in his little School Physiology, it may be stated as follows. The heat which is communicated to the blood in every living part of the body by the chemical changes which constitute its life, is distributed therefrom to every other part by the blood-stream; but between the external parts-i.e., those which are in contact with relatively cool external media-and the internal parts, there is this important difference, that whereas in the interior all is production, at the exterior the production is far more than balanced by the loss-i.e., by the giving off of heat by evaporation and radiation : consequently, if it were not that by means of the circulation fresh supplies of heat are constantly being brought to the surface from the warmer parts at the centre, the surface would rapidly cool, as indeed it actually does when the circulation is much weakened. Hence; in respect of its function in the distribution of heat, the circulation is rightly compared by physiological teachers, to a hot-water apparatus; and they use this similitude, be it observed, not as a representation of the facts, but merely as a diagram or schema. Even for this purpose the ordinary hot water apparatus requires considerable modification in its plan, in order tu serve as an illustration. In the first place, we must suppose that the movement of the water is determined, not, as in the ordinary case, by the variations of density due to heat, but by the action of a pump representing the heart; and that the heat is communicated to the water, not at one focus, the stove, but in all parts of the system (as $e . g$, still following our friend Huxley, by a number of little gas jets arranged at short intervals underneath the pipes); and secondly, we must have our pump placed at the centre of the system, and our waterpipes, some in protected positions close to each other and carefully covered with hay ropes and other appliances for preventing loss of heat, others exposed to the air, divided by repeated branching and kept constantly moist, to represent the conditions of the circulation in the exposed and external parts of the body. So arranged, the apparatus would give us a very true diagram of the circulation in relation to the distribution of heat, and it is not difficult to see what the results would be, both as regards the maintenance of temperature in the whole system, and its distribution in different parts. The temperature of the internal protected tubes wonld be always greater, that of the external exposed tubes always less, than the mean temperature of the whole apparatus ; but, provided that the dryness and temperature of the external media and the relative quantities of water passing to the external and internal parts, and the heat communicated by the gas jets remained unchanged, the mean temperature of the whole system would be constant, just as it is in the animal body. Any alteration of any of these factors would declare itself either in general warming or cooling, which, however, would only go on until a new balance of loss and gain was established. If, e.g., the relative quantity of water flowing through the external parts were increased, either by facilitating the flow in the protected tubes or by hindering it in the exposed ones, this would at once tell in an increase of the general temperature in the whole system, which effect would continue until, by increased evaporation and more rapid radiation at the exposed surfaces, equilibrium was again established. The former condition representing health, this might be regarded as fever.

Out of considerations of this sort sprang the two theories of fever to which we now desire to direct our attention. According to Marey, fever consists in a general relaxation of the vascular system of the external parts of the body; referring to our schema, we find that the effect of this must be to let blood of a higher temperature from the central pump flow more freely into them and warm them up. Hence the hot skin of fever. According to Traube, on the contrary, the surface vessels are contracted. Consequently the flow of blood through the exposed parts is hindered, while that through the internal organs remains unimpeded. Hence, again referring to the schema, the general temperature of the body rises, and you have fever. Is it not strange that on the same physiological scaffolding such opposite structures should be erected?

The vaso-motor theory of fever in either of its forms is not only defective as leaving the collateral constituents of the febrile state (viz., those which relate to nutrition and secretion) unaccounted for, but fails to explain even the very phenomena (those of circulation and bodily temperature) on which it is constructed. It is perfectly true that in the animal body as in the schema, if we alter the relative quantity of blood flowing in external and internal parts, or vary the velocity of the blood stream, we produce corresponding variations both in the distribution of temperature and in the mean temperature of the body. But experiment shows-1, that the maximum effect thus produced is not comparable in quantity to the elevation of temperature actually observed in fever; and
2, that the direction in which the effect manifests itself varies, being determined by complicated combinations of circumstances of which neither theory takes any account. These are, among others, the external temperature at the time, and the vigour with which the heart responds to the increased resistance. Considering that we can produce much more decided vaso-motor effects experimentally than any which can be supposed to exist in fever, and can graduate those effects at will, we may consider it as proved, at all events as regards vascular contraction, that this condition is quite inadequate to account even for the temperature result attributed to it.

The notion that the heat of skin in fever is dependent upon what may be called a determination of blood to the surface, is in like manner negatived by the fact previously referred to in relation to the regulation theory that under all varieties of condition the invariable effect of vascular relaxation is the contrary to that which the theory supposes, viz., to depress the bodily temperature, and that this cooling takes place even when the animal is protected as much as possible from the in. fluence of external media by packing it in cotton wool and so forth. A more striking, though not to the physiologist, a more conclusive proof of the inadequacy of any conceivable change in the distribution of the blood to produce pyrexia is to be found in an experiment of Liebermeister's, of which I will now endeavour to give an account. It is an experiment not made on dog, cat, or rabbit, but on a willing human subject. It can, however, be substantially repeated on the lower animals with a similar result.

If you take two ordinary warm baths at the temperature of the body, and, after careful agitation of the water, put a healthy person in the one, leaving the other unoccupied, the mass of water in each being the same, and then after a time remove the subject of experiment, and again measure the temperature of the water after agitation, it is found-I, that, whereas in the unoccupied bath the temperature of the water has sunk, the occupied bath has either remained at the same temperature, or at all events has lost less than the other ; and 2, that the subject's body has become warmer, because, being surrounded entirely with a conducting medium neither cooler nor warmer than itself, no heat whatever has been lost at the surface ; so that all the internal heat produced during the period of immersion has accumulated, that is to say, has gone to the good of the bodily temperature.

This is the experiment. Its value lies in the information it gives us as to the maximum result which can possibly be attained by complete suppression of the surface discharge by mere accumulation of the heart normally produced. The thermometrical results of the experiment as compared with temperature measurements, e. $g$., in intermittent fever during the period of fervescence, show that the rate at which the temperature rises in the accession of ague is at least four times as great as the maximum effect of accumulation.

I need scarcely say that I have not exhausted all the theories of fever in the sketch I have attempted to give of those which propose to explain its phenomena by attributing them either to vascular disturbance on the one hand, or to paralysis of a supposed regulating centre on the other. I now proceed to the second use that I wish to make of my example, to try to show what is the true method of investigation in pathological questions.

How must this question of fever be attacked? It seems to be too strong a position to be carried by assault, and must be got at by a combination of well directed approaches. The questions must be taken as they present themselves, one by one. This done, the combining of the results into a theory will require as little genius as the taking of a fortress requires military skill from the moment that all the commanding positions are already in the hands of the besiegers.

The first step is to select among the constituent phenomena of fever those which are the most important-in other words, to classify the characteristics of the febrile state according to the greater or less degree in which they are essential. This can of course be done on one prin. ciple only, that according to which those phenomena are regarded as most important which are most constantly present. On this principle we have no difficulty in placing pyrexia first ; next comes, probably, loss of weight ; next frequency of pulse, and after these other concomitant phenomena more or less dependent on them.

Taking pyrexia as a phenomenon by itself we want to know how it can be produced. We have but two certainties to start from ; first, that in the animal body heat is produced exclusively by chemical change; secondly, that in the particular case to be investigated the rate at which the body is warmed is greater than can be accounted for by any mere accumulation. The first of these propositions is axiomatic, being an almost immediate consequence of the law of conservation of force; the second arises from experiments like that of Liebermeister on the human subject, as well as from others more exact on animals. By the combination of these two propositions we come to the conclusion that such an 
increase of temperature as occurs in fever must depend on increased oxidation.

The next question relates to the seat of the process-where does such increased oxidation occur? Here we have no sufficient information Admitting that the most probable answer is-everywhere, that is, that just as heat is produced normally in every tissue it must be so produced in fever, it would be most unjustifiable to assume that it is so.

Of the three or four tissues of which the mass of the animal body is composed-the nervous, the glandular, the connective, and the muscular-there is one only which has as yet been sufficiently investigated in its relation to ordinary heat production, viz., the muscular. With respect to this tissue, it cannot be shown that it is the special seat of the increased chemical activity which produces fever, but it can be shown that even if every other source of heat production were excluded the variations of intensity of which muscular oxidation is capable would be sufficient quantitatively to account for the variations of bodily temperature which occur in fever. In this respect, therefore, I propose to refer to some of the experimental facts known to physiology as to this heat-producing function of muscle.

I will first mention an experiment which belongs neither to the laboratory nor to the hospital, our two ordinary sources of information. A man works in an extremely hot place, for example the stoke-hole of a tropical steam vessel, where he is subject to a temperature of perhaps 120 to 130 degrees F. Under such circumstances a dog would soon die, but so efficient is the apparatus for the discharge of heat at the surface in the human body, that not only life but continued muscular work is possible. If now we place the same man under slightly altered circumstances, and set him to work in what is termed a "dead end" in one of the so-called " hot mines" in Cornwall, where not only the air is heated, but the workman is rained upon by the incessant dripping of water at a temperature of say 105 degrees $F$. so that the air is constantly saturated with moisture, we find that, although the temperature is nothing like so high as in the stoke-hole, he suffers so much more from the effect of it that continued labour is impossible. After remaining by a great effort of the will for ten minutes at the most, he can endure the distress no longer, but rushes out to cool himself, and after a few minutes' rest in a well ventilated gallery is himself again.

To understand the difference between the two cases, all we have to do is to compare the man's bodily temperature as he escapes exhausted from the hot working with that which he possesses while labouring in the stoke-hole. In both instances there is excessive production of heat, and as we know from other experiments excessive discharge from the body of carbonic acid, but in the one the over-production is balanced by the surface cooling, in the other such cooling is impossible, the man's body itself receiving the overplus, which goes on accumulating until, if I may use the expression, he is warmed up into fever-a fever which although transitory, yet so long as it lasts shows all the characteristics of the febrile state-the quick pulse, the muscular and nervous prostration, the increased temperature, and increased discharge of oxidised products.

The experiment $I$ have been relating is a ready made one, and may be called a rough one ; it exemplifies the physiological fact that the excessive heat production which is determined by muscular exertion, if not compensated for by increased discharge, raises the bodily temperature and thus produces functional disorders which closely correspond to those of fever.

The same thing may be demonstrated with greater exactitude by experiments on animals. Nothing, e.g., could be more striking by way of lllustration of the heat-producing function of muscle than the comparison of the effect of the two well known poisons, curare and strychnia, on bodily temperature-curare by paralysing the muscles, cooling the body so effectually that, as every experimenter knows, it is impossible, with the utmost precautions, to prevent the temperature from sinking; while, under the influence of strychnia, the heat produced is so much increased that the temperature rapidly rises to that of fever.

I trust that, after what has been said, it is scarcely necessary to observe that I am not drifting towards a new theory of pyrexia. My object is not to show that fever has its seat in muscle, but that any process by which vital activity can be increased in a relatively large mass of living tissue is capable of producing a pyrexia which is, in every respect, excepting its cause, a counterpart of that of fever. Of the bearing of this conclusion, we can judge better if we put it into another form ; for in other words it amounts to this, that pyrexia may be produced by any agent, whether originating in the nervous system, as in the case of the man working in the hot mine, or in the blood, as in the case of the animal poisoned by strychnia, which stimulates a great mass of living tissue to increased action. In this way we come back to a very old definition of fever-that fever is the reaction of the living organism against a stimulus. This definition is of value merely as a finger-post, as an indicator of the direction in which we must work. I understand it to mean that, if I am to seek suceessfully for the proximate cause of fever, I must look for it among agents which act either directly or in. directly as excitors or irritants of living tissue. Examples of indirect action I have already given. I now proceed to submit to your consideration a third example, which I conceive to be one of direct action.

It has now come to be an extremely well-known fact in pathology that if the exudation liquids of certain acute inflammations are mixed even in extremely small quantity with the blood-stream, the inevitable result is the production of a pyrexia, which in its development, progress, and concomitant phenomena, so far as they have yet been studied, exhibits all the characters of the febrile state. I have no intention of entering at all into the consideration of this remarkable process, and refer to it here merely by way of illustration. I am altogether unable to state on what tissue mass the poison in question exercises its influence; all I want to do is to point out that whatever answer is eventually given by experiment to this question, the only possible conception that can be formed of its mode of action is that which regards it as a direct tissue stimulant.

I have not time to enter upon the other constituents of fever, each of which requires as careful and separate investigation as that of pyrexia - the phenomenon of shivering and the changes which accompany it in the circulation, affecting the arterial pressure and the distribution of the blood to different parts ; the changes which occur in the hygrometric condition of the skin and mucous membrane, and in the glandular ap. paratus connected with the latter; the changes which occur in the tissues in fever, so well investigated by Dr. Beale in the fever of cattleplague; and last, but not least, the chemical changes which occur in the blood. Each of these requires to form the subject of a separate and detailed investigation, and until this is carried out it is premature to go any further in theorising than is necessary for the purpose of obtaining what I have already indicated as finger posts.

I have now come to the end of my time if not of your patience, and I must attempt what I feel myself singularly incompetent for-I must appeal to you to use all your influence to promote the prosecution of pathological research in this country.

Having this in view, I chose the subject of fever, partly because I am myself deeply interested in it, and partly because fever and inflam. mation have always in the history of medicine been the pivots on which pathological teaching has turned. If therefore pathology is of any value at all, if it is of use to know not only the external characteristics on which we base our diagnosis of disease, but the internal and hidden processes which constitute its essence, the question of fever cannot fail to interest us. But it is not in support of this or that line of inquiry in particular that I would appeal to you. What I would urge is that this Association ought to help forward pathological research as a thing distinct from, though highly serviceable to practical medicine and surgery ; that we should support it, not merely on the ground of its immediate utility, or of the direct applicability of the results to be obtained, but on the broad principle of its scientific value.

As regards the eventual utility of scientific research in general it is not needful for me to address you. You have heard the subject argued, and probably read the numercus publications which have recently appeared in connection with the work of the Royal Scientific Commission, the result of whose labours I earnestly hope may be to obtain from our legislature a permanent recognition of the national importance of research. As regards physical science in general, indeed, there can I think be no doubt that eventually, and it is to be hoped at no very distant period, this country, which owes its boundless wealth no less to its scientific men than to its statesmen, will tardily but freely and fully acknowledge its obligation.

It is quite possible that our science will not at first participate in the advantages of this change. The question whether it does so or not will, I think, much depend upon the medical profession, of which this Association is the representative body.

By the earnest and energetic pleading of men belonging to our profession, the public ear has been successfully gained for the claims of other branches of physical science not immediately connected with medicine. At the present moment we have a scientific inquiry in progress on a large scale at the public expense which has for a principal object the investigation of a physiological question, viz., that of the physical conditions which govern the distribution of living beings at the bottom of the deep sea. Many of us, I do not doubt, take a deep interest in the success of this undertaking, for the carrying out of which the best instrumental appliances have been provided, and the most skilful and carefully trained observers selected.

I do not refer to this expedition because I think that the magnificent preparations which have been made are at all out of proportion to the 
importance of the objects. I refer to it for the purpose of making a comparison between these inquiries and those in which we as pathologists are interested. The able staff of naturalists on board the Chal. lenger concern themselves with the animals which inhabit the depths of the ocean, and with the conditions which affect their life-we occupy ourselves with human beings and the physical agents which affect their life. These agents are altogether similar in their nature to the others, and require the same methods for their investigation.

We do not for a moment doubt that the care and thought which has been spent in the case of the Challenger expedition in the selection of competent persons as observers, in organising them under a man of science of acknowledged ability, in dividing the work of research among different individuals, in providing them with proper places to work in, and proper instruments to work with, has been wisely spent.

Let us, if we desire to promote efficient research in our own province, follow the same principle. Let us not suppose that because in the past history of medicine the employment of an hour here and an hour there, of weary leisure stolen, as it were, from the practical duties of a laborious profession, has accomplished great things, that this is the most efficient way of proceeding now. It must be admitted that circumstances have changed, and that as we possess resources which before did not exist we ought to use them. In the first place we have young men trained in the methods of chemical and physical work, who no doubt would show themselves as zealous and devoted to experimental researches in physiology and pathology as the young men now on board the Challenger in their several lines of inquiry; we have long had hospitals as fields of investigation, and now we have laboratories for the proper carrying on of our work. What we chiefly require is organisation, a clear definition of the purposes to be attained, and a combination of the various agencies at our disposal towards their attainment.

I venture to think that it is an object in every respect worthy of this great Association to further and promote the organisation of physiological and pathological research, by fixing on the questions to be investigated, by appointing persons of acknowledged scientific ability to take the direction of the inquiries, by encouraging young men of the highest ability to devote the earlier years of professional life to research, and by providing the necessary funds.

GALVANISM IN POST PARTCM HAMORRHAGE.

THE following case may be considered of interest, as furnishing an instance of the efficiency of a mode of treatment for the great opprobrium of obstetric art, which, if not new and little known, is at any rate far from being so widely employed as its numerous advantages would appear to indicate that it should be.

The patient was in an extremely feeble state of health, and subject to epileptiform seizures. Convulsions came on during the first stage of labour, and could only be checked by keeping her under the influence of chloroform for some time. Failure of uterine action occurred before the os uteri was fully dilated ; but as it was sufficiently dilatable, forceps (Beattie's) were introduced, and delivery was accomplished. Still, the uterus did not contract, and, after the placenta was removed, hæmorrhage could only be restrained by keeping the hand within the uterus. Grasping and kneading the uterus, cold affusion externally, and injections of cold water pervaginam, produced no effect. A dilute solution of perchloride of iron was freely injected into the uterus, but proved ineffectual. The employment of galvanism was then suggested as a dernier ressort, and one of Stöhrer's portable coil machines was procured. An interrupted current of considerable intensity was directed through the uterus, one pole of the battery being applied to the abdominal walls immediately over the fundus, by means of a curved plate of copper, and the other placed in the cervix. Almost immediately firm contraction took place; and when the current was discontinued after a short time, the uterus remained securely contracted, and no further haemorrhage took place. The patient made a good recovery.

To those who have often witnessed, as it has probably been the lot of most general practitioners to do, the bustle and confusion and other disagreeable accessories of a case of obstinate hæmorrhage after labour, any means that tends to diminish these inconveniences must be most acceptable. The use of galvanism as a means of treatment in these cases, besides its remarkable efficiency, as shown by the foregoing case, and which might naturally be expected, judging from its action on contractile tissues generally, possesses many other advantages over the means usually employed ; for instance, the cleanliness and simplicity of its mode of application, and the avoidance of those evil consequences in the puerperal state which are so apt to result from the irritation of the uterus, and the exposure and deluging with cold water which usually take place. Therefore it is to be hoped that its efficiency may soon become established beyond doubt, and its employment become as general as it deserves to be.

\section{A N A D D R E S S}

DELIVERED AT THE OPENING OF

\section{THE SECTION OF MEDICINE.}

At the Annual Meeting of the British Medical Association, in London, August I873.

BY FRANCIS SIBSON, M.D., F.R.S., V.P.R.S., Consulting Physician to St. Mary's Hospital, President of the Section.

Gentiemen, - Ten years have passed away since the Association met in London, under the distinguished presidency of Dr. Burrows; and during that brief period our numbers have almost trebled themselves, and the science of medicine has made a remarkable and solid advance. This Medical Section, and the various sister sections into which our Association, obeying the true laws of evolution, has divided itself, have come into being since our former meeting in this metropolis ; and this, you will agree with me, is a fitting time and place to take a brief glance at the past, the present, and the probable future of medicine, and at the past, the present, and the possible future influence of this Medical Section on the science of medicine.

When I was a student in Edinburgh more than forty years ago, Dr Home gave us eleven wearisome lectures on the treatment of fever and how to cut fever short; and his ninth lecture begins thus in my notebook: "Exanthematous fevers cannot be cut short." You will not find one word on the method of cutting fevers short in the whole of Dr. Murchison's recent great work on Continuced Fever. Sir Thomas Watson's masterly letter on the cattle-plague gives expression, in a few brief and clear lines, to our present knowledge of fever and its treatment. Every physician now knows that fever cannot be shortened by one day; and his efforts are directed, like a skilful pilot guiding his boat down the rapids, to the treatment, not of the fever as such, but of the effects of the fever through which the patient must pass. It has been well suggested to me that the physician, in the treatment of a case of fever, resembles the accoucheur in the management of parturition. The labour may advance favourably, and require little aid ; but difficul. ties may occur during its progress that would be fatal but for the aid afforded by the obstetrician.

I will not revive the bloodletting controversy-a subject brought before this Association with admirable force by Dr. Stokes on the one hand, and elsewhere by Dr. Hughes Bennett and Dr. Markham on the other. I feel, however, that many of those patients into whose arm a lancet is now never inserted, would have been freely bled if they had been treated in the bygone days of which I have just spoken. During the many oscillations in the type of disease that have taken place during the last thirty years, the lancet has not been brought into use in this country. It is otherwise, however, in Italy and in Spain, where, I am told, bleedings from both arms, and leeches elsewhere, are the usual practice in acute diseases.

At the very time of which I have been speaking, Dr. Alison in Edinburgh, whose memory is cherished by every student of that day, and Henlé in Germany, and soon afterwards Dr. Sharpey in London, were, by their physiological labours, laying the foundations for that more secure knowledge of disease and its treatment that now prevails.

It is a remarkable illustration of the present direction of the medical mind, that the admirable Address in Medicine by Dr. Parkes, to which we have just listened with such advantage and close attention, and the coming Address in Physiology by Dr. Sanderson, are, or will be, the contributions of two of the physicians who, in this country, have done more than any others to bring physiology and exact inquiry to bear on our knowledge of disease and its treatment. This spirit of exact inquiry into the most intimate functions of life during health and disease, and under the influence of treatment, by means of self-recording instruments of precision, of volumetric analysis, and other agencies, is the spirit of our time. Ludwig, by applying the kymograph to the hæmo. dynamometer in 1848 , enabled the pressure of the blood to write its own story ; and Dr. Sanderson relates that "the notion of the kymograph is said to have been suggested by a contrivance of Watt's for registering the pressure of the steam-engine."

Investigation and action - the investigation of each case of disease, and prompt action in its treatment, give life and zest, with its mingled care and hope, to the daily work of every physician. The more complete study of disease and its treatment can, however, only be carried on in the ward, the mortuary, and the laboratory. For this purpose, however, the laboratory ought to be transferred to the ward. The cardiograph of Marey, the recording stethometer of Dr. Sanderson, 